\title{
New Challenges in Medical Thoracoscopy
}

\author{
Marios E. Froudarakis \\ Department of Pneumonology, Medical School, Democritus University of Thrace, Alexandroupolis, Greece
}

\section{Key Words}

Thoracoscopy, infrared $\cdot$ Narrow band imaging $\cdot$ Flex-rigid thoracoscope $\cdot$ Autofluorescence $\cdot$ Pneumothorax $\cdot$ Pleural effusion

\begin{abstract}
Thoracoscopy is currently the gold standard for the diagnosis and treatment of pleural diseases. Its diagnostic yield is 95\% in patients with malignant pleural disease, with approximately $90 \%$ successful pleurodesis for malignant pleural effusion and $95 \%$ for pneumothorax. At the same time, thoracoscopy constitutes an important tool in the research of pleural pathophysiology and molecular biology. The improvement of technology has provided important tools to thoracoscopy, such as autofluorescence, narrow band imaging, and infrared light, used in clinical and basic research in many disorders involving the pleura. For these reasons, training in thoracoscopy should be considered equally important as training in bronchoscopy for residents in respiratory medicine.

Copyright $\odot 2011$ S. Karger AG, Basel
\end{abstract}

\section{Introduction}

One century after the Swedish physician Hans Christian Jacobaeus first introduced a cystoscope into the pleural cavity of a patient with pleural tuberculosis, thoracoscopy has been definitely abandoned as a therapeutic approach for tuberculosis. This technique, however, is now considered the gold standard for the diagnosis and treatment of most pleural disorders [1], and it currently achieves a diagnostic yield of $95 \%$ in patients with malignant pleural disease $[2,3]$. Its success rate in creating pleurodesis for malignant pleural effusion [3] and pneumothorax [4] is 90 and $95 \%$, respectively. Apart from its good performance in diagnosing the cause of a pleural effusion, in recent years this technique has continuously developed not only in terms of new and advanced devices for the improvement of the diagnostic yield but also in clinical and basic research for many disorders involving the pleura [5].

\section{Development of New Tools and Devices}

The development of different devices over the years has changed the concept of thoracoscopy. The classic procedure involves rigid devices, using 8 - to $11-\mathrm{mm}$ trocars, 7- to $10-\mathrm{mm}$ optics, and 4- to 6-mm forceps. More recently, the technique of minithoracoscopy has allowed the use of a smaller, 4-mm trocar with a 3.3-mm telescope and $3-\mathrm{mm}$ forceps in patients with undiagnosed pleural effusion [6]. Visualization using minithoracoscopic instrumentation is excellent, allowing a thorough inspection of the pleural space. The main limitations of this technique are difficulties related to the lysis of adhesions and a $20 \%$ increase in the duration of the intervention [6]. However, the diagnostic yield of minithoracoscopy is $93 \%$, making it equal to the classic rigid technique, with an excellent cosmetic result [6].

Thoracoscopy was also performed with a flexible bronchoscope in the late 1970s to 1980s [5]. Flexible bronchoscopes failed to show equal diagnostic accuracy due to their fully flexible bodies [7] and thus led to the development of a device with a rigid body and a flexible tip.

\section{KARGER}

Fax +4161306 1234

E-Mail karger@karger.ch

www.karger.com
(C) 2011 S. Karger AG, Basel

0025-7931/11/0882-0197\$38.00/0

Accessible online at:

www.karger.com/res
Marios E. Froudarakis, MD, $\mathrm{PhD}$

Department of Pneumonology

University Hospital of Alexandroupolis

GR-68100 Alexandroupolis (Greece)

Tel. +30 255107 5335, E-Mail mfroud@ med.duth.gr 
This new thoracoscope (LTF 160 or 240; Olympus, Tokyo, Japan) has a handle and a shaft measuring $7 \mathrm{~mm}$ in outer diameter and $27 \mathrm{~cm}$ in length. The shaft is made up of 2 sections: a $22-\mathrm{cm}$ proximal rigid portion and a $5-\mathrm{cm}$ flexible distal end. The flexible tip can be moved using a lever on the handle which allows 2-way angulation. It has a $2.8-\mathrm{mm}$ working channel that accommodates biopsy forceps and other accessories used for flexible bronchoscopy and gastrointestinal endoscopy, which are all available in most endoscopy units. This combination insures flexibility for a better inspection of the pleural cavity and, at the same time, improves biopsy sampling with its rigid part. The diagnostic accuracy of a flex-rigid thoracoscope in cases of undiagnosed pleural effusion is the same as that of rigid devices (on average 93\%) $[8,9]$ although the number of patients included in the flex-rigid studies is limited [1]. Its resemblance to a flexible bronchoscope, and its similar handling, have also helped to spread the technique [1].

The development of the flex-rigid thoracoscope allowed the possibility of using technologies until then reserved only for fiber-optic devices, paving the way to possible future developments in medical thoracoscopy [5]. The narrow band imaging (NBI) device is now used to recognize and determine differences in tissue microcirculation between malignant and benign diseases of the pleura in patients with undiagnosed pleural effusion [10]. NBI has the ability to enhance blood vessels using 2 narrow bands of light which have absorption spectrum peaks of hemoglobin within the visible wavelength of light. Using NBI, neo-angiogenesis is recognizable in malignant pleural disease by the development of a heterogeneous vessel caliber via CD34 staining of microvascular proliferation [10]. Since molecular staging of malignancies today is becoming a 'must' in the expansion of the use of targeted therapy [11], this important observation opens up a new area of research [1].

In patients with non-small cell lung cancer, visceral pleural invasion is a poor prognostic factor $[12,13]$. Invasion of the visceral pleura is confirmed by means of pathologic examination. Sometimes, however, it is not possible for a pathologist to clearly ascertain tumor invasion. A jet stream of saline solution performed intraoperatively allows pleural lavage. This method seems to be more accurate than routine pathological techniques in detecting visceral pleura invasion by lung carcinoma [12]. Patients with positive cytology from intraoperative pleural lavage showed significantly poorer survival than did those with negative cytology [12]. Pleural lavage is possible during thoracoscopy [14]. It is a useful tool for the study of pleural physiology. A step forward in treating patients with non-small cell lung cancer and peripheral lesions could be the systematic investigation of pleural cytology and therefore the demonstration of micrometastatic disease. This would lead to a more precise prediction of survival and hence to a better management of these patients.

Another device recently used to increase the diagnostic yield of thoracoscopy is fluorescence [15]. Autofluorescence excitation in the system used in patients with undiagnosed exudative pleural effusion [15] (R. Wolf GmbH, Knittlingen, Germany) is achieved by means of a $300-\mathrm{W}$ xenon lamp in the violet-blue range $(390-460 \mathrm{~nm})$. The combination of white light thoracoscopy and autofluorescence thoracoscopy can improve the diagnostic yield in those patients. Sensitivity is $100 \%$ but specificity is low (75\%). The calculated positive predictive value is $92 \%$ [15].

\section{Challenges in Pathophysiology and Treatment of Pleural Diseases}

The pathogenesis of primary spontaneous pneumotho$\operatorname{rax}(\mathrm{PSP})$ is under investigation. Thoracoscopy has been used after inhalation of fluorescein to study its distribution in animals [16] and to detect bullae in patients with PSP (fig. 1). Additional findings suggested substantial areas of parenchymal abnormalities [17]. Satellite areas of abnormal parenchymal lesions could only be identified by fluorescein-enhanced autofluorescence in normal subjects during thoracoscopy for other causes [18]. Another technique applied to investigate bullous or emphysematous lesions of the lung parenchyma is infrared thoracoscopy [19]. The lung lesions are demonstrated in white, whereas normal lung tissue is imaged in blue, under infrared thoracoscopy. Moreover, small bullous lesions are detectable with infrared thoracoscopy because of its clearer visualization compared with white light thoracoscopy. The decreased blood flow of bullous lesions is detected by a decreased indocyanine green intensity [19]. After injection of indocyanine green, infrared thoracoscopy shows the area of normal perfusion in blue, whereas the area at which perfusion is absent remains white [20]. By identifying those lesions which are otherwise undetectable, both autofluorescence and infrared thoracoscopy are a step forward in understanding the pathophysiology of PSP [1].

Thoracoscopic talc poudrage using European large particle size calibrated asbestos-free talc is considered the gold standard for pleurodesis in patients with malignant pleural effusion. Its efficacy, achieving a long-lasting 


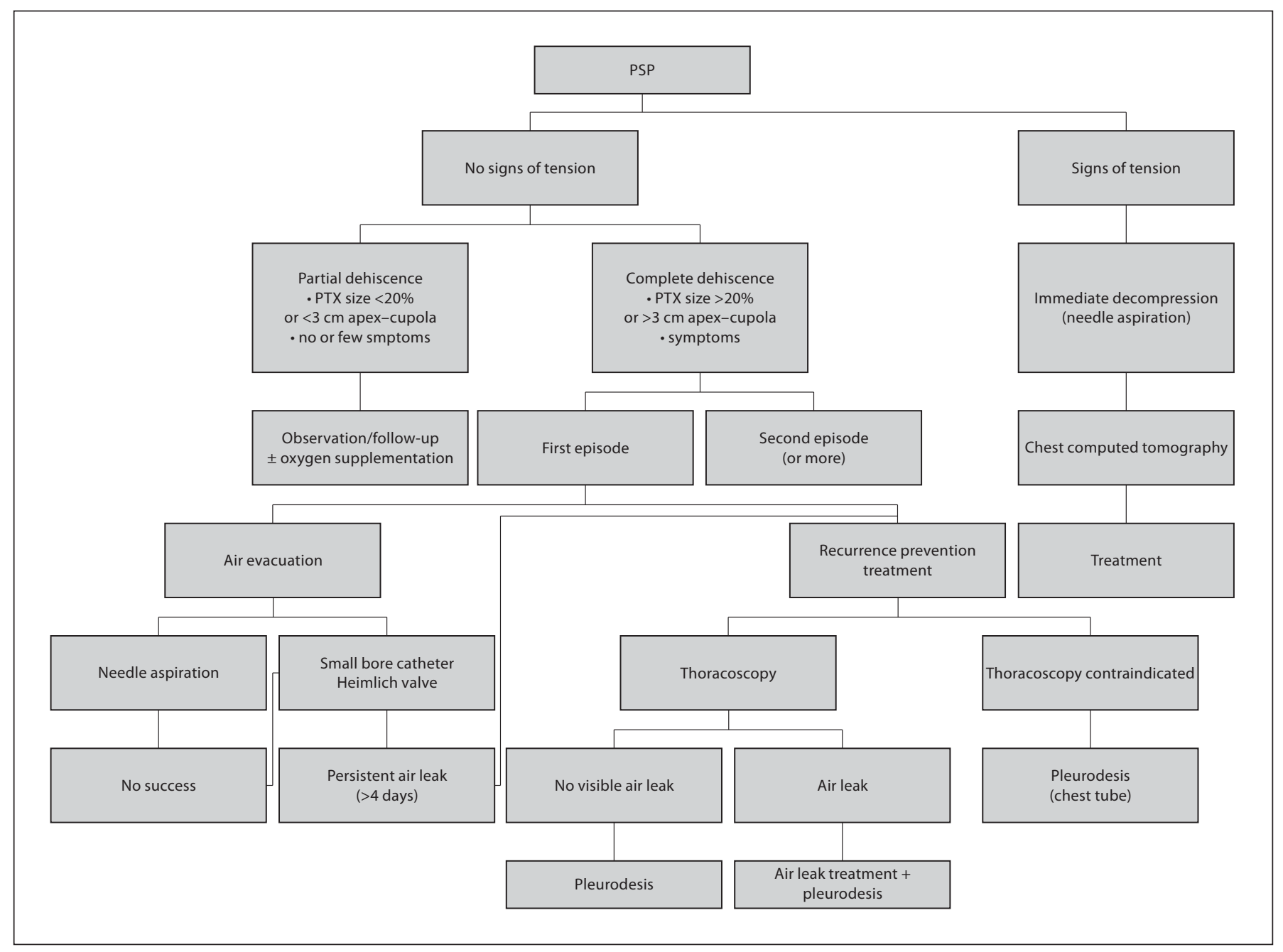

Fig. 1. Place of medical thoracoscopy in the management of PSP (modified from the report by Noppen and De Keukeleire [4]). PTX = Pneumothorax.

pleurodesis at a very low cost $[3,21]$, is over $90 \%$. In pneumothorax, nonrandomized reports showed a significant benefit of thoracoscopic pleurodesis when compared with blebs or bullae resection alone. [22, 23]. Furthermore, thoracoscopic talc pleurodesis in patients with PSP has significantly lower recurrence rates, shorter durations of hospitalization, and lower costs compared with chest tube drainage [24]. Simple thoracoscopy pleurodesis costs 3 times less than VATS or thoracotomy with bullectomy and pleural abrasion in patients with PSP [25]. The rationale for not resecting blebs and/or bullae is that the presence of blebs and/or bullae has never been proved to be a real risk factor of PSP occurrence $[4,26,27]$. The need for a phase III randomized study comparing surgical procedures to simple thoracoscopy talc pleurodesis is warranted to definitively select the best management of patients with PSP $[26,27]$.

An unsolved issue in the management of patients with pleural infection is whether these patients should undergo early thoracoscopy or classical treatment. Up to $40 \%$ of patients undergo surgical drainage after either videoassisted thoracic surgery or thoracotomy with pleural decortication [28]. Although early minimal intervention with thoracoscopy has shown excellent results in recent reports [29], the need for a controlled large phase III trial to further define its place in the treatment of pleural infection is required [30] since the few studies reporting results with a small number of patients are not sufficient to draw conclusions [31]. 


\section{Conclusion}

Thoracoscopy is the oldest interventional technique in respiratory medicine. During the past century, thoracoscopy has become a research tool by contributing new ideas and concepts to the study of the pathophysiological and molecular mechanisms of pleural disorders. Its impact in the diagnosis and treatment of pleural diseases has increased in recent years. Clinical trials should, however, define the role of thoracoscopy in the management of specific diseases. Further improvement of technologies will provide important tools for the research, diagnosis, and treatment of pleural disorders. For these reasons, training in thoracoscopy and training in bronchoscopy should be considered equally essential for residents in respiratory medicine.

\section{References}

1 Froudarakis ME, Noppen M: Medical thoracoscopy: new tricks for an old trade. Respiration 2009;78:373-374.

$\checkmark 2$ Froudarakis ME: Diagnostic work-up of pleural effusions. Respiration 2008;75:4-13.

-3 Rodriguez-Panadero F: Medical thoracoscopy. Respiration 2008;76:363-372.

4 Noppen M, De Keukeleire T: Pneumothorax. Respiration 2008;76:121-127.

5 Froudarakis ME: Thoracoscopy one century later: the oldest interventional technique of modern pneumonology, with great future prospects. Pneumon 2010;23:28-33.

6 Tassi G, Marchetti G: Minithoracoscopy: a less invasive approach to thoracoscopy. Chest 2003;124:1975-1977.

7 Davidson AC, George RJ, Sheldon CD, Sinha G, Corrin B, Geddes DM: Thoracoscopy: assessment of a physician service and comparison of a flexible bronchoscope used as a thoracoscope with a rigid thoracoscope. Thorax 1988;43:327-332.

8 Lee P, Hsu A, Lo C, Colt HG: Prospective evaluation of flex-rigid pleuroscopy for indeterminate pleural effusion: accuracy, safety and outcome. Respirology 2007;12:881-886.

9 Munavvar M, Khan MA, Edwards J, Waqaruddin Z, Mills J: The autoclavable semirigid thoracoscope: the way forward in pleural disease? Eur Respir J 2007;29:571-574.

10 Ishida A, Ishikawa F, Nakamura M, Miyazu YM, Mineshita M, Kurimoto N, Koike J, Nishisaka T, Miyazawa T, Astoul P: Narrow band imaging applied to pleuroscopy for the assessment of vascular patterns of the pleura. Respiration 2009;78:432-439.

-11 Sienel W, Dango S, Ehrhardt P, Eggeling S, Kirschbaum A, Passlick B: The future in diagnosis and staging of lung cancer: molecular techniques. Respiration 2006;73:575580.

12 Lim E, Ali A, Theodorou P, Nicholson AG, Ladas G, Goldstraw P: Intraoperative pleural lavage cytology is an independent prognostic indicator for staging non-small cell lung cancer. J Thorac Cardiovasc Surg 2004;127: 1113-1118.

13 Maruyama R, Shoji F, Okamoto T, Miyamoto T, Miyake T, Nakamura T, Ikeda J, Asoh $\mathrm{H}$, Yamaguchi $\mathrm{M}$, Yoshino I, Ichinose $\mathrm{Y}$ : Prognostic value of visceral pleural invasion in resected non-small cell lung cancer diagnosed by using a jet stream of saline solution. J Thorac Cardiovasc Surg 2004;127:15871592.

-14 Noppen M, De Waele M, Li R, Gucht KV, D'Haese J, Gerlo E, Vincken W: Volume and cellular content of normal pleural fluid in humans examined by pleural lavage. Am J Respir Crit Care Med 2000;162:1023-1026.

15 Chrysanthidis MG, Janssen JP: Autofluorescence videothoracoscopy in exudative pleural effusions: preliminary results. Eur Respir J 2005;26:989-992.

16 Vandermeulen L, Makris D, Mordon S, Goossens A, Marquette CH, Haentjens P, Noppen M: Thoracoscopic findings and pharmacokinetics of inhaled fluorescein in a pig model. Respiration 2010;80:228-235.

17 Noppen M, Stratakos G, Verbanck S, D’Haese J, Meysman M, Vincken W: Fluorescein-enhanced autofluorescence thoracoscopy in primary spontaneous pneumothorax. Am J Respir Crit Care Med 2004;170:680-682.

18 Noppen M, Dekeukeleire T, Hanon S, Stratakos G, Amjadi K, Madsen P, Meysman M, D'Haese J, Vincken W: Fluorescein-enhanced autofluorescence thoracoscopy in patients with primary spontaneous pneumothorax and normal subjects. Am J Respir Crit Care Med 2006;174:26-30.

19 Gotoh M, Yamamoto Y, Igai H, Chang S, Huang C, Yokomise H: Clinical application of infrared thoracoscopy to detect bullous or emphysematous lesions of the lung. J Thorac Cardiovasc Surg 2007;134:1498-1501.

20 Misaki N, Chang SS, Gotoh M, Yamamoto Y, Satoh K, Yokomise H: A novel method for determining adjacent lung segments with infrared thoracoscopy. J Thorac Cardiovasc Surg 2009;138:613-618.

21 Bouros D, Froudarakis M, Siafakas NM: Pleurodesis: everything flows. Chest 2000; 118:577-579.

22 Horio H, Nomori H, Kobayashi R, Naruke T, Suemasu K: Impact of additional pleurodesis in video-assisted thoracoscopic bullectomy for primary spontaneous pneumothorax. Surg Endosc 2002;16:630-634.

23 Loubani M, Lynch V: Video assisted thoracoscopic bullectomy and acromycin pleurodesis: an effective treatment for spontaneous pneumothorax. Respir Med 2000;94:888890

-24 Tschopp JM, Boutin C, Astoul P, Janssen JP, Grandin S, Bolliger CT, Delaunois L, Driesen P, Tassi G, Perruchoud AP: Talcage by medical thoracoscopy for primary spontaneous pneumothorax is more cost-effective than drainage: a randomised study. Eur Respir J 2002;20:1003-1009.

25 Schramel FM, Sutedja TG, Braber JC, van Mourik JC, Postmus PE: Cost-effectiveness of video-assisted thoracoscopic surgery versus conservative treatment for first time or recurrent spontaneous pneumothorax. Eur Respir J 1996;9:1821-1825.

-26 Tschopp JM, Schnyder JM, Astoul P, Noppen M, Froudarakis M, Bolliger CT, Gasparini S, Tassi GF, Rodriguez-Panadero F, Loddenkemper R, Aelony Y, Janssen JP: Pleurodesis by talc poudrage under simple medical thoracoscopy: an international opinion. Thorax 2009;64:273-274, author reply 4.

27 Tschopp JM, Schnyder JM, Froudarakis M, Astoul P: VATS or simple talc poudrage under medical thoracoscopy for recurrent spontaneous pneumothorax. Eur Respir J 2009;33:442-443.

28 Davies W, Kearney S, Gleeson F, Davies R: Predictors of outcome and long-term survival in patients with pleural infection. Am J Respir Crit Care Med 2003;160:1682-1686.

29 Brutsche MH, Tassi GF, Gyorik S, Gokcimen M, Renard C, Marchetti GP, Tschopp JM: Treatment of sonographically stratified multiloculated thoracic empyema by medical thoracoscopy. Chest 2005;128:3303-3309.

30 Wiegand J, Tschopp JM, Froudarakis M, Tassi G, Brutsche M, ESMITTE Study, Group: A randomized controlled study of early mini-invasive medical thoracoscopy vs simple chest tube drainage in complicated parapneumonic effusions or pleural empyema - ESMITTE (European Study on MiniInvasive Thoracoscopy in Empyema) - an intermediate report. Proc Am Thorac Soc 2006;3:A540.

31 Coote N, Kay ES: WITHDRAWN: Surgical versus non-surgical management of pleural empyema. Cochrane Database Syst Rev 2009;7:CD001956. 